\title{
KAJIAN EKONOMI USAHATANI HORTIKULTURA PADA KELOMPOK WANITA TANI PERKOTAAN DI BOGOR
}

\author{
THE ECONOMIC STUDY OF HORTICULTURE BUSINESSES \\ IN URBAN FARMING FEMALE GROUPS IN BOGOR
}

\author{
Anak Agung Eka Suwarnata*, Nia Sonani, Agista Rosiana \\ Universitas Nusa Bangsa, Jalan K.H. Sholeh Iskandar Km.4, \\ Kelurahan Cibadak, Kecamatan Tanah Sareal, Kota Bogor, Indonesia \\ *E-mail: 1985.agungeka@gmail.com \\ (Diterima 16-12-2020; Disetujui 2-1-2021)
}

\begin{abstract}
ABSTRAK
Peran kelompok tani di perkotaan sangat dibutuhkan dalam pengembangan komoditas hortikultura karena diperkirakan permintaan komoditas hortikultura akan meningkat seiring pertambahan jumlah penduduk. Hal ini tentu menjadi peluang usaha yang baik bagi petani perkotaan khususnya kelompok wanita tani (KWT) perkotaan. Tujuan penelitian ini adalah mengkaji secara ekonomi usahatani hortikultura pada KWT perkotaan di Bogor ditinjau aspek pendapatan serta efisiensi penggunaan biaya usahatani. Lokasi penelitian di 52 KWT Kota Bogor dari bulan Juni-November 2020. Pengumpulan data menggunakan alat kuesioner, teknik survei, observasi wawancara, dan studi dokumentasi. Kajian menggunakan analisis pendapatan usahatani, sedangkan analisis efisiensi diukur dengan R/C Ratio. Hasil penelitian kajian secara ekonomi diperoleh rata-rata pendapatan tunai usahatani hortikultura pada KWT di Bogor per tahun per luas $487 \mathrm{~m}^{2}$ adalah senilai Rp3.514.080,75 atau setara dengan Rp7.203.865,55/tahun/10 are, sedangkan rata-rata pendapatan total senilai Rp1.190.686,16 per $487 \mathrm{~m}^{2}$ atau setara dengan Rp2.440.906,62/tahun/10 are. Nilai $\mathrm{R} / \mathrm{C}$ rasio atas biaya tunai adalah 4,24 , dan $\mathrm{R} / \mathrm{C}$ rasio atas biaya total, diperoleh nilai 1,37 yang berarti usahatani hortikultura pada KWT di Bogor efisien untuk dijalankan karena input yang ditargetkan berbanding input aktual lebih besar atau sama dengan satu.
\end{abstract}

Kata kunci: pendapatan, efisiensi, usahatani, hortikultura

\begin{abstract}
The role of farmer groups in urban areas is very much needed in the development of horticultural commodities because it is estimated that the demand for horticultural commodities will increase as the population increases. This is certainly a good business opportunity for urban farmers, especially urban female farmer groups (KWT). The purpose of this research is to examine economically horticultural farming in urban KWT in Bogor in terms of income aspects and the efficiency of using farm costs. The research location was at $52 \mathrm{KWT}$ Bogor City from JuneNovember 2020. Collecting data using questionnaires, survey techniques, interview observation, and documentation study. The study used farm income analysis, while the efficiency analysis was measured by the $R / C$ ratio. The results of the economic study showed that the average cash income of horticultural farming at KWT in Bogor per year per area of $487 \mathrm{~m} 2$ was IDR 3,514,080.75 or equivalent to IDR 7,203,865.55 / year / 10 are, while the average total income worth IDR 1,190,686.16 per $487 \mathrm{~m} 2$ or equivalent to IDR 2,440,906.62 / year / 10 are. The $R$ / $C$ value of the ratio of cash costs is 4.24, and the $R / C$ ratio of total costs, the value is 1.37 , which means that horticultural farming in KWT in Bogor is efficient to run because the targeted input compared to the actual input is greater or equal to one.
\end{abstract}

Keywords: income, efficiency, farming, horticulture 


\section{KAJIAN EKONOMI USAHATANI HORTIKULTURA PADA \\ KELOMPOK WANITA TANI PERKOTAAN DI BOGOR \\ Anak Agung Eka Suwarnata, Nia Sonani, Agista Rosiana}

PENDAHULUAN

Kebutuhan lahan yang semakin meningkat mengakibatkan semakin langkanya lahan pertanian yang mendukung budidaya pertanian yang unggul sehingga memerlukan optimalisasi penggunaan sumberdaya lahan yang memungkinkan tetap tersedianya lahan untuk pertanian secara berkelanjutan. Tantangan ini merupakan salah satu masalah dan tantangan serius dalam pertanian di Indonesia (Ahmadi, 2006), yang ditambah lagi dengan adanya persaingan penggunaan lahan untuk sektor non pertanian. Salah satu kegiatan yang mampu menjawab tantangan ini adalah kegiatan pertanian perkotaan.

Kegiatan pertanian perkotaan secara umum memiliki peranan yang sangat penting karena diperlukan alam mendukung ketahanan pangan dengan ketersediaan pangan yang cukup, kemampuan untuk mengakses (termasuk membeli) pangan, dan tidak terjadinya ketergantungan pangan pada pihak manapun, maka kedudukan petani dalam kegiatan pertanian perkotaan memiliki posisi strategis untuk mendukung ketahanan pangan. Hal ini disebabkan karena petani adalah produsen pangan dan juga sekaligus kelompok konsumen terbesar (Cahya, 2014).
Pertanian perkotaan selain mempunyai manfaat ekonomi, juga mempunyai manfaat sosial dan manfaat lingkungan. Hal ini sejalan dengan hasil penelitian Slabinski yang menyimpulkan bahwa pertanian perkotaan dapat menjadi salah satu solusi karena tidak hanya menjadikan lahan kosong menjadi berguna tetapi juga memberikan solusi murah dan fleksibel bagi masyarakat yang kesulitan finansial (Slabinski, 2013).

Hasil penelitian Hubert De Bon et al menyimpulkan bahwa kegiatan pertanian akan terus menjadi kontributor utama bagi masyarakat perkotaan dan perbedaan pertanian pedesaan dengan pertanian perkotaan semakin menurun. Fungsi supply makanan bagi masyarakat perkotaan menjadikan pertanian perkotaan perlu diperhatikan oleh penduduk, pemerintah, dan petani di perkotaan. Serta isu utamanya adalah memproduksi hasil pertanian kualitas tinggi di kawasan padat penduduk dan lingkungan yang polusi. Produksi yang dapat dihasilkan pada kawasan padat penduduk atau perkotaan adalah komoditas hortikultura (De Bon, Parrot, \& Moustier, 2009).

Kota Bogor, sebagai salah satu sentra komoditas hortikultura diharapkan 
mampu berperan dalam pengembangan tanaman hortikultura. Peran kelompok tani di perkotaan sangat dibutuhkan dalam pengembangan komoditas hortikultura karena diperkirakan permintaan komoditas hortikultura akan meningkat seiring pertambahan jumlah penduduk. Selain itu, kita ketahui bahwa kejadian tidak terduga di bulan Maret 2020, COVID-19 menyerang Kota Bogor hingga saat ini. Pangan hortikultura sangat dibutuhkan untuk memenuhi kebutuhan keluarga saat tinggal di rumah. Hal ini tentu menjadi peluang usaha yang baik bagi petani perkotaan khususnya kelompok wanita tani perkotaan yang secara umum melakukan kegiatan usahatani hortikultura. Hortikultura adalah segala hal yang berkaitan dengan buah, sayuran, bahan obat nabati, dan florikultura, termasuk di dalamnya jamur, lumut, dan tanaman air yang berfungsi sebagai sayuran, bahan obat nabati, dan/atau bahan estetika (Kementerian Hukum dan Hak Asasi Manusia, 2010).

Upaya peningkatan produksi tanaman hortikultura khususnya di Kelompok Wanita Tani, tidak lepas dari beberapa kendala yang dihadapi seperti adanya keterbatasan modal antara lain: luas lahan, bibit, pupuk, obat-obatan dan tenaga kerja (Sa'diyah, A. A., Muljawan,
2011). Bertolak dari pemikiran tersebut, kiranya perlu dilakukan penelitian tentang kajian ekonomi usahatani hortikultura pada Kelompok Wanita Tani di Kota Bogor.

Tujuan penelitian ini adalah mengkaji secara ekonomi usahatani hortikultura pada Kelompok Wanita Tani (KWT) perkotaan di Bogor ditinjau dari aspek pendapatan, efisiensi penggunaan biaya usahatani.

\section{METODE PENELITIAN}

Lokasi penelitian ditentukan secara sengaja yaitu di Kota Bogor. Pertimbangan pemilihan lokasi ini adalah Kota Bogor merupakan wilayah perkotaan dan masyarakatnya aktif dalam kegiatan pertanian perkotaan, terdapat Kelompok Wanita Tani yang berperan dalam menciptakan ketahanan dan kemandirian pangan, serta telah menghasilkan produk pertanian. Waktu penelitian berlangsung selama 6 (enam) bulan, dari bulan Juni sampai November 2020. Jenis penelitian adalah kuantitatif dengan teknik survei. Variabel penelitian yaitu biaya tunai, biaya yang diperhitungkan, total biaya, penerimaan, dan pendapatan KWT di Bogor.

Populasi penelitian ini adalah seluruh Kelompok Wanita Tani (KWT) 
yang berada di Kota Bogor berjumlah 106 kelompok, tersebar di 6 (enam) Kecamatan dan 68 Kelurahan (Pertanian, 2020). Pengambilan sampel dilakukan dengan metode nonprobability sampling yaitu teknik purposive sampling (Sugiyono, 2011) dengan kriteria yaitu KWT yang memulai kegiatan dari sarana produksi, produksi/budidaya, dan pemasaran hasil produk hortikultura. Luas lahan yang diusahakan berkisar 0,001 hektare sampai 0,5 hektare, dan mengusahakan lebih lebih dari satu tanaman pada lahan yang sama selama satu tahun. Penentuan ukuran sampel menggunakan rumus Slovin (Amirin, 2011).

$n=\frac{\mathrm{N}}{\left(1+\left(\mathrm{N} \mathrm{x} \mathrm{e}^{2}\right)\right.}$

\section{Keterangan:}

n: jumlah sampel

$\mathrm{N}$ : jumlah populasi

e: nilai kritis (batas ketelitian 10\%) yang digunakan persen kelonggaran.

Hasil diperoleh 51 KWT yang tersebar di enam Kecamatan se-Kota Bogor.

Pengumpulan data menggunakan teknik survei, observasi wawancara, dan studi dokumentasi secara langsung ke lokasi usahatani hortikultura yang dikelola oleh Kelompok Wanita Tani
Kota Bogor. Pengumpulan data dilakukan dengan menggunakan alat kuesioner (Sugiyono, 2011).

Metode pengolahan data menggunakan metode deskriptif kualitatif dan kuantitatif. Analisis kualitatif dijelaskan secara deskriptif mengenai usahatani hortikultura pada Kelompok Tani perkotaan di Bogor. Analisis data kuantitatif menggunakan data hasil kuesioner. Pengolahan data dibantu dengan software Microsoft Excel 2010 dan kalkulator. Pendapatan petani diukur menggunakan analisis pendapatan usahatani, sedangkan analisis efisiensi diukur dengan $\mathrm{R} / \mathrm{C}$ Ratio.

Analisis pendapatan usahatani akan menggambarkan secara kuantitatif pendapatan yang diperoleh petani dari berusahatani hortikultura (Soekartawi, 2016). Perhitungan analisis usahatani tersebut menggunakan penjabaran rumus yang diuraikan sebagai berikut.

$T R=P y . Y$

Keterangan:

$\mathrm{TR}=$ Total Revenue (penjumlahan penerimaan tunai dan non tunai dalam rupiah)

Py = Harga Output (harga komoditas hortikultura dalam rupiah per kilogram) 
$\mathrm{Y}=$ Jumlah Output (produk komoditas hortikultura dalam kilogram)

Pendapatan tunai $=$ Penerimaan - Biaya tunai

Pendapatan total usahatani (total farm income) merupakan selisih antara penerimaan total dengan biaya total, dengan rumus Pendapatan Total = Penerimaan total - Biaya total.

Pengukuran efisiensi masingmasing usahatani terhadap setiap penggunaan satu unit input dapat digambarkan oleh nilai rasio antara jumlah penerimaan dengan jumlah biaya (R/C). R/C rasio yang dihitung dalam analisis ini terdiri dari $\mathrm{R} / \mathrm{C}$ atas biaya tunai dan $\mathrm{R} / \mathrm{C}$ atas biaya total, yang secara sederhana dapat diturunkan dari rumus:

$$
\begin{aligned}
& R / C_{\text {tunai }}=\frac{\text { Penerimaan Total }}{\text { Biaya Tunai }} \\
& R / C_{\text {total }}=\frac{\text { Penerimaan Total }}{\text { Biaya Total }}
\end{aligned}
$$

Keterangan:

$\mathrm{R}=$ Revenue atau penerimaan $(\mathrm{Rp})$

$\mathrm{C}=$ Cost atau pengeluaran ( $\mathrm{Rp})$

Nilai R/C secara teoritis menunjukkan bahwa setiap satu rupiah biaya yang dikeluarkan akan memperoleh penerimaan, jika $\mathrm{R} / \mathrm{C}>1$ maka kegiatan usahatani efisien untuk dijalankan, apabila $\mathrm{R} / \mathrm{C}<1$ maka kegiatan usahatani tidak efisien untuk dijalankan (Soekartawi, 1984).

\section{HASIL DAN PEMBAHASAN}

Pada hasil dan pembahasan penelitian dipaparkan karakteristik responden yaitu ketua atau anggota Kelompok Wanita Tani (KWT) yang telah menjawab isian kuesioner, hasil data dan pembahasan biaya, penerimaan, pendapatan, serta efisiensi usahatani hortikultura KWT di Bogor.

\section{Karakteristik Responden}

Penyerapan dan pengambilan keputusan dalam penerapan teknologi dan inovasi dalam usahatani dipengaruhi oleh faktor umur (Yulida \& Indraningsih, 2012). Usia responden penelitian berada pada rentang 34 tahun sampai 69 tahun, dengan umur rata-rata responden adalah 51 tahun yang berarti usia rata-rata petani masih dalam usia produktif dan berpengaruh terhadap kinerja KWT. Hal ini sesuai dengan hasil penelitian Widyawati yang menyatakan umur petani wanita berpengaruh dan signifikan terhadap curahan waktu kerja (Widyawati, 2013).

Pada data responden berdasarkan tingkat pendidikan diperoleh $52 \%$ atau 27 orang pendidikan SMA/sederajat, $25 \%$ 


\section{KAJIAN EKONOMI USAHATANI HORTIKULTURA PADA \\ KELOMPOK WANITA TANI PERKOTAAN DI BOGOR \\ Anak Agung Eka Suwarnata, Nia Sonani, Agista Rosiana}

atau 13 orang pendidikan SMP/sederajat, $17 \%$ atau sembilan orang pendidikan Perguruan Tinggi, dan 6\% atau tiga orang berpendidikan SD/sederajat. Tingkat pendidikan dan pengetahuan seseorang akan membantu untuk berpikir global dan penuh pertimbangan dalam mengelola usahatani (Widyawati, 2013).

Pengalaman bertani berpengaruh terhadap produksi usahatani. Hal ini disebabkan karena dengan pengalaman yang dimiliki, petani mampu menghadapi permasalahan yang ada (Artanegara, Setiawina, \& Djayastra, 2016). Hasil data pengalaman responden berusahatani paling lama 17 tahun dan paling cepat baru satu tahun. Data lama pengalaman berusahatani disajikan pada Tabel 1 .

Tabel 1. Lama Pengalaman Responden dalam Berusahatani pada Kelompok Wanita Tani di Bogor

\begin{tabular}{cccc}
\hline No & $\begin{array}{c}\text { Lama } \\
\text { Pengalaman } \\
\text { (tahun) }\end{array}$ & $\begin{array}{c}\text { Jumlah } \\
\text { (orang) }\end{array}$ & $\begin{array}{c}\text { Persentase } \\
(\%)\end{array}$ \\
\hline 1 & $1-5$ & 25 & 48 \\
2 & $6-10$ & 10 & 19 \\
3 & $11-15$ & 12 & 23 \\
4 & $>15$ & 5 & 10 \\
\hline & Jumlah & 52 & 100 \\
\hline
\end{tabular}

Sumber: Analisis Data Primer (2020)

Tabel 1 menunjukkan lama pengalaman berusahatani dari satu sampai dengan lima tahun terbanyak. Makin lama pengalaman bertani, akan mempengaruhi produktivitas usahatani (Sugiantara, I.G.N. Made \& Utama, 2019).
Data luas pengusahaan lahan hortikultura oleh responden dapat dilihat pada Tabel 2 .

Tabel 2. Luas Pengusahaan Lahan Usahatani Hortikultura pada Wanita Tani di Bogor

\begin{tabular}{cccc}
\hline No & $\begin{array}{c}\text { Luas Lahan } \\
\left(\mathrm{m}^{2}\right)\end{array}$ & $\begin{array}{c}\text { Jumlah } \\
\text { (orang) }\end{array}$ & $\begin{array}{c}\text { Persentase } \\
(\%)\end{array}$ \\
\hline 1 & $<700$ & 40 & 77 \\
2 & $700-1800$ & 9 & 17 \\
3 & $>1800$ & 3 & 6 \\
\hline & Jumlah & 52 & 100 \\
\hline
\end{tabular}

Sumber: Analisis Data Primer (2020)

Pada Tabel 2 dapat dilihat persentase terbesar pada pengusahaan lahan hortikultura dengan luas $<700 \mathrm{~m}^{2}$. Hal ini disebabkan terbatasnya lahan untuk pertanian di wilayah perkotaan. Rata-rata pengusahaan lahan hortikultura oleh KWT di Bogor adalah $487 \mathrm{~m}^{2}$.

Status kepemilikan lahan responden, disajikan pada Tabel 3.

Tabel 3. Status Kepemilikan Lahan KWT di Bogor

\begin{tabular}{clcc}
\multicolumn{4}{c}{ Bogor } \\
No & $\begin{array}{c}\text { Status } \\
\text { Kepemilikan } \\
\text { Lahan }\end{array}$ & Jumlah & $\begin{array}{c}\text { Persentase } \\
(\%)\end{array}$ \\
\hline 1 & $\begin{array}{l}\text { Milik kelompok } \\
\text { Sewa } \\
\text { Milik orang luar } \\
\text { anggota/Bagi } \\
\text { hasil }\end{array}$ & 25 & 48 \\
4 & $\begin{array}{l}\text { Milik pemerintah/ } \\
\text { swasta } \\
\text { Gabungan (milik } \\
\text { dan sewa) }\end{array}$ & 16 & 12 \\
\hline & Jumlah & 52 & 100 \\
\hline
\end{tabular}

Sumber: Analisis Data Primer (2020)

Pada Tabel 3 dapat dilihat data sebaran status kepemilikan lahan hortikultura KWT Bogor dengan nilai 
tertinggi $48 \%$ adalah status lahan usahatani milik kelompok. Guna memanfaatkan lahan agar menjadi produktif, KWT di Bogor juga berusahatani menggunakan lahan milik pemerintah/ fasilitas umum.

Komoditas hortikultura kategori sayur yang diusahakan oleh KWT di Bogor dapat dilihat pada Gambar 1.

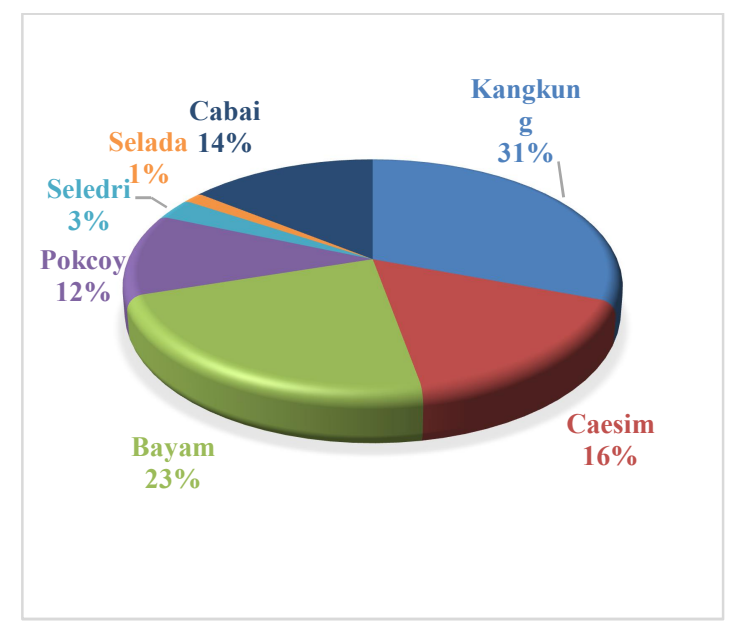

Gambar 1. Persentase Jenis Komoditas Usahatani Hortikultura Sayur pada KWT di Bogor

Gambar 1 menunjukkan bahwa hortikultura jenis sayur kangkung dan bayam banyak diusahakan oleh KWT di Bogor. Beberapa alasan tanaman kangkung dan bayam banyak diusahakan oleh KWT di Bogor karena jenis sayur tersebut mudah diusahakan, memiliki masa panen yang pendek sekitar 25 hari setelah masa tanam (Edi, 2010). Selain kangkung dan bayam, KWT di Bogor juga mengusahakan caisim, pokcoy, seledri, selada, dan cabai.
Komoditas hortikultura jenis buah yang banyak diusahakan oleh KWT di Bogor adalah pisang dan pepaya. Alasannya adalah buah tersebut diminati masyarakat kota karena bermanfaat untuk kesehatan. Pisang kaya akan vitamin dan serat, memiliki lebih dari dua kali lipat karbohidrat, dan lima kali lipat vitamin A, kaya magnesium dan kalium yang penting bagi tubuh untuk tetap bugar (P2PTM Kemenkes, 2018). Selain itu, pisang dan papaya mudah ditanam, murah dan mudah dalam perawatan. Selain pisang dan papaya, komoditas hortikultura buah yang diusahakan oleh KWT adalah paria, terong, tomat, kacang panjang, buncis, timun, mangga, nanas, dukuh, timun sari, jeruk nipis, jeruk limau, sirsak, alpukat, rambutan, manggis, pala, jambu biji, jambu kristal, mengkudu, belimbing, stroberi, dan melon.

Selanjutnya, komoditas hortikultura jenis tanaman obat yang banyak ditanam oleh KWT di Bogor adalah jahe merah dan kunyit. Sebagian besar tanaman jahe merah yang diusahakan KWT di Bogor merupakan bentuk kerja sama Pemerintah Kota Bogor dengan PT Bintang Toejoe yang memiliki tujuan meningkatkan produksi jahe merah (Nadia, 2018). Komoditas tanaman obat lain yang 
diusahakan dan dipasarkan oleh KWT di Bogor adalah kumis kucing, bunga telang, bawang dayak, lidah buaya, daun kelor, daun mint, binahong, kunyit, lengkuas, daun sirih, daun salam, sereh, jinten, kencur, dan temulawak.

Komoditas hortikultura aglonema dan anggrek adalah jenis florikultura yang sebagian besar ditanam oleh KWT di Bogor. Kedua jenis tanaman tersebut diusahakan karena diminati oleh pencinta tanaman hias karena bentuknya unik dan menarik (Putri, 2020). Florikultura lain yang diusahakan KWT di Bogor adalah athorium, lidah mertua, puring dan bunga matahari.

\section{Analisis Pendapatan Usahatani}

\section{Hortikultura}

Analisis pendapatan usahatani merupakan gambaran secara kuantitatif pendapatan yang diterima petani dari berusahatani (Soekartawi, 2016). Analisis pendapatan usahatani hortikultura pada KWT di Bogor terdiri dari dua perhitungan yaitu pendapatan tunai dan pendapatan total usahatani hortikultura dalam satu tahun.

\section{Pendapatan Tunai}

Pendapatan tunai diperoleh dari penerimaan usahatani hortikultura dikurangi biaya tunai dalam usahatani hortikultura. Total biaya tunai usahatani hortikultura pada KWT di Bogor dapat dilihat pada Tabel 4.

\begin{tabular}{cccc} 
Tabel 4. & $\begin{array}{c}\text { Total Biaya } \\
\text { Hortikultura } \\
\text { Bogor per Tahun }\end{array}$ & $\begin{array}{c}\text { Tunai } \\
\text { pada }\end{array}$ & \multicolumn{2}{c}{ Usahatani } \\
& & \multicolumn{2}{c}{$\begin{array}{c}\text { Total Biaya Tunai } \\
\text { (Rp/tahun) }\end{array}$} \\
\hline No & & Uraian & $3.640 .300,00$ \\
& & $3.624 .638,94$ \\
\hline 1 & Benih & $48.304 .500,00$ \\
2 & Bibit & $8.164 .312,50$ \\
3 & Pupuk & $1.375 .920,00$ \\
4 & TKLK & $950.000,00$ \\
5 & Pengairan (PDAM) &
\end{tabular}

Tabel 5. Rata-rata Biaya Tunai Usahatani Hortikultura pada KWT di Bogor/Tahun/487 $\mathrm{m}^{2}$

\begin{tabular}{clr}
\hline No & Uraian & $\begin{array}{c}\text { Rata-rata } \\
\text { Biaya Tunai } \\
\text { (Rp/tahun) }\end{array}$ \\
\hline 1 & Benih & $72.806,00$ \\
2 & Bibit & $109.837,54$ \\
3 & Pupuk & $928.932,69$ \\
4 & TKLK & $291.582,59$ \\
5 & Pengairan (PDAM) & $275.184,00$ \\
6 & Sewa lahan & $475.000,00$ \\
\hline \multicolumn{2}{l}{ Sumber: Analisis Data Primer (2020) }
\end{tabular}

Tabel 4 dan 5 menunjukkan total dan rata-rata biaya tunai pupuk organik paling banyak dikeluarkan atas biaya tunai KWT di Bogor. Penggunaan pupuk organik dipilih karena banyak bahan organik daripada kadar haranya (Suriadikarta, Didi Ardi., Simanungkalit, 2006). Selain itu, pupuk organik mengandung unsur hara makro dan mikro, mampu mengefektifkan bahanbahan anorganik di dalam tanah, memiliki daya ikation yang tinggi, 
memperbaiki struktur tanah, sehingga pertumbuhan tanaman bisa optimal (Parnata, 2004). Biaya terbesar kedua adalah Tenaga Kerja Luar Kelompok (TKLK). KWT di Bogor merupakan petani wanita dalam mengusahakan tanaman hortikultura, belum sepenuhnya menggunakan tenaga kerja dalam kelompok. Oleh sebab itu, KWT menggunakan jasa tenaga kerja dari Kelompok Tani Dewasa (KTD) laki-laki untuk mengolah tanah dengan rata-rata upah harian Rp77.500,00.

Selanjutnya, penerimaan tunai usahatani hortikultura KWT diperoleh dari harga dalam rupiah masing-masing komoditas hortikultura yang diproduksi KWT, dikalikan dengan jumlah produksi komoditas hortikultura KWT dalam satuan kilogram. Setelah diketahui biaya tunai dan penerimaan usahatani hortikultura, selanjutnya dianalisis pendapatan tunai usahatani hortikultura KWT di Bogor. Hasil analisis rata-rata penerimaan usahatani hortikultura senilai Rp4.784.459,05 per tahun. Rata-rata biaya tunai senilai Rp1.270.378,30 per tahun. Total pendapatan tunai yang diperoleh KWT di Bogor dalam usahatani hortikultura adalah senilai Rp182.732.199,19 dengan rata-rata pendapatan tunai senilai Rp3.515.080,75 per tahun. Hasil analisis disajikan pada Tabel 6.

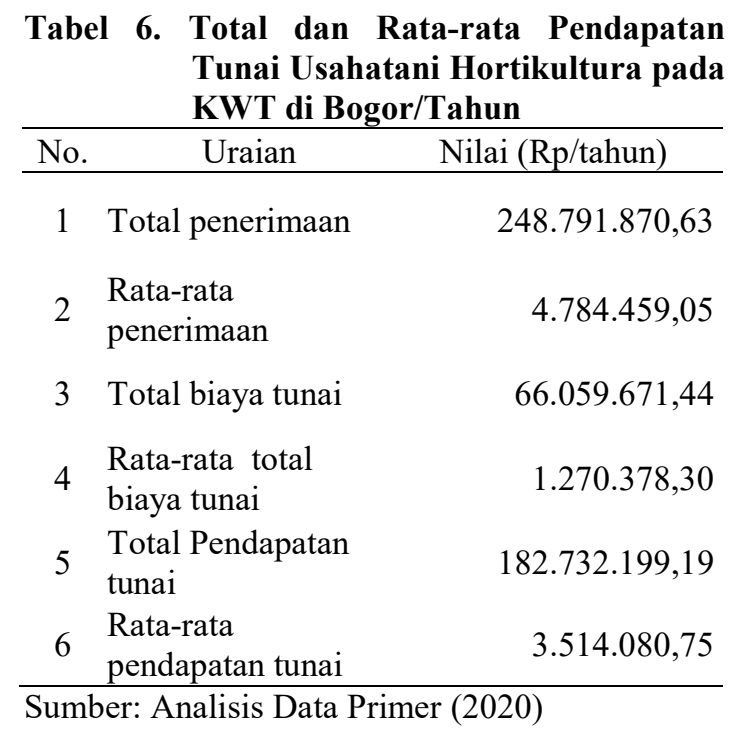

\section{Pendapatan Total}

Pendapatan total diperoleh dari penerimaan usahatani hortikultura dikurangi biaya total dalam usahatani hortikultura. Biaya total diperoleh dari penjumlahan biaya total tunai dengan biaya total diperhitungkan. Hasil analisis biaya total dan rata-rata diperhitungkan disajikan pada Tabel 7 dan 8 .

Tabel 7. Total Biaya Diperhitungkan dalam Usahatani Hortikultura pada KWT di Bogor/Tahun

\begin{tabular}{clr}
\hline No & Uraian & \multicolumn{1}{c}{$\begin{array}{c}\text { Total Biaya } \\
\text { Diperhitungkan } \\
(\mathrm{Rp} / \text { tahun })\end{array}$} \\
\hline 1 & Penyusutan & $21.975 .875,00$ \\
2 & TKDK & $48.905 .354,13$ \\
3 & Benih & $331.500,00$ \\
4 & Bibit & $5.487 .000,00$ \\
5 & Pupuk & $470.000,00$ \\
6 & Pengairan & $15.053 .040,00$ \\
\hline \multicolumn{2}{l}{ Sumber: Analisis Data Primer (2020) }
\end{tabular}


Tabel 8. Rata-rata Biaya Diperhitungkan dalam Usahatani Hortikultura pada KWT di Bogor/Tahun/487 $\mathbf{m}^{2}$

\begin{tabular}{clr}
\hline No & Uraian & \multicolumn{2}{c}{$\begin{array}{c}\text { Rata-rata Biaya } \\
\text { Diperhitungkan } \\
\text { (Rp/tahun/487 m2) }\end{array}$} \\
\hline 1 & Penyusutan & $422.612,98$ \\
2 & TKDK & $940.487,58$ \\
3 & Benih & $55.250,00$ \\
4 & Bibit & $119.282,61$ \\
5 & Pupuk & $94.000,00$ \\
6 & Pengairan & $313.605,00$ \\
7 & Lahan & $581.500,00$ \\
\hline
\end{tabular}

Sumber: Analisis Data Primer (2020)

Tabel 7 dan 8 menunjukkan total dan rata-rata biaya diperhitungkan paling besar berada pada tenaga kerja dalam kelompok (TKDK) KWT. Nilai tersebut diperhitungkan karena dalam KWT anggota kelompok terlibat dalam usahatani hortikultura. Biaya diperhitungkan lainnya adalah lahan dan penyusutan aset. Penggunaan lahan pemerintah, swasta, lahan milik anggota kelompok diluar sewa dan bagi hasil, pengairan dengan sumber air sumur, pupuk, bibit dan benih bantuan pemerintah, diperhitungkan dalam analisis.

Hasil analisis pendapatan total usahatani hortikultura pada KWT di Bogor per tahun senilai Rp61.915.680,07 dengan rata-rata total pendapatan dengan rata-rata luas lahan $487 \mathrm{~m}^{2}$ senilai Rp1.190.686,16. Hasil analisis data disajikan pada Tabel 9.
Tabel 9. Pendapatan Total dan Rata-rata pada Usahatani Hortikultura di KWT Bogor per Tahun

\begin{tabular}{rlr}
\hline No. & Uraian & Nilai (Rp/tahun) \\
\hline 1 & Total penerimaan & $248.791 .870,63$ \\
2 & Rata-rata penerimaan & $4.784 .459,05$ \\
3 & Total biaya tunai & $66.059 .671,44$ \\
4 & $\begin{array}{l}\text { Rata-rata total biaya } \\
\text { tunai }\end{array}$ & $1.270 .378,30$ \\
5 & $\begin{array}{l}\text { Total biaya } \\
\text { diperhitungkan }\end{array}$ \\
6 & $\begin{array}{l}\text { Rata-rata total biaya } \\
\text { diperhitungkan }\end{array}$ \\
7 & $\begin{array}{l}\text { Total biaya } \\
\text { (tunai+diperhitungkan) }\end{array}$ & $120.816 .519,13$ \\
8 & Rata-rata total biaya & $3.593 .772,90$ \\
9 & $\begin{array}{l}\text { Pendapatan total } \\
\text { Rata-rata total } \\
10\end{array}$ & $\begin{array}{l}\text { pendapatan } \\
\text { Sumber: Analisis Data Primer (2020) }\end{array}$
\end{tabular}

Tabel 9 menujukkan pendapatan total usahatani hortikultura KWT di Bogor per tahun senilai Rp61.915.680,07 dengan rata-rata total pendapatan dengan rata-rata luas lahan $487 \mathrm{~m}^{2}$ senilai Rp1.190.686,16.

\section{Analisis Efisiensi Usahatani}

Nilai rasio antara jumlah penerimaan dengan jumlah biaya menggambarkan pengukuran efisiensi masing-masing usahatani terhadap setiap penggunaan satu unit input. Hasil analisis efisiensi usahatani hortikultura pada KWT di Bogor disajikan pada Tabel 10. 
Tabel 10. Analisis R/C Rasio atas Biaya Tunai dan Diperhitungkan pada Usahatani Hortikultura di KWT Bogor per Tahun

\begin{tabular}{clr}
\hline No. & Uraian & Nilai (Rp/tahun) \\
\hline 1 & Rata-rata penerimaan & $4.784 .459,05$ \\
2 & $\begin{array}{l}\text { Rata-rata total biaya } \\
\text { tunai }\end{array}$ & $1.270 .378,30$ \\
3 & $\begin{array}{l}\text { Rata-rata total biaya } \\
\text { diperhitungkan }\end{array}$ & $2.323 .394,60$ \\
4 & Rata-rata total biaya & $3.593 .772,90$ \\
5 & $\begin{array}{l}\text { R/C rasio atas biaya } \\
\text { tunai }\end{array}$ & 4,24 \\
6 & $\begin{array}{l}\text { R/C rasio atas biaya } \\
\text { total }\end{array}$ \\
\hline Sumber: Analisis Data Primer (2020) & 1,37 \\
\end{tabular}

Sumber: Analisis Data Primer (2020)

Tabel 10 dijelaskan nilai $\mathrm{R} / \mathrm{C}$ rasio atas biaya tunai adalah 4,24 yang berarti setiap Rp1.000,00 biaya tunai yang dikeluarkan oleh KWT di Bogor untuk berusahatani hortikultura, memberikan penerimaan sebesar Rp4.240,00. Begitu juga dengan $\mathrm{R} / \mathrm{C}$ rasio atas biaya total, diperoleh nilai 1,37 yang berarti setiap KWT di Bogor mengeluarkan Rp1.000,00 akan memperoleh penerimaan sebesar Rp1.370,00. Hal ini berarti usahatani hortikultura pada KWT di Bogor efisien untuk dijalankan karena input yang ditargetkan berbanding input aktual lebih besar atau sama dengan satu (Soekartawi, 1984).

\section{KESIMPULAN DAN SARAN}

Kajian secara ekonomi diperoleh hasil rata-rata pendapatan tunai usahatani hortikultura pada KWT di Bogor per tahun per luas $487 \mathrm{~m}^{2}$ adalah senilai
Rp3.514.080,75 atau setara dengan Rp7.203.865,55/tahun/10 are, sedangkan rata-rata pendapatan total senilai Rp1.190.686,16 per $487 \mathrm{~m}^{2}$ atau setara dengan Rp2.440.906,62/tahun/10 are.

Nilai $\mathrm{R} / \mathrm{C}$ rasio atas biaya tunai adalah 4,24, dan $\mathrm{R} / \mathrm{C}$ rasio atas biaya total, diperoleh nilai 1,37 yang berarti usahatani hortikultura pada KWT di Bogor efisien untuk dijalankan karena input yang ditargetkan berbanding input aktual lebih besar atau sama dengan satu.

Berdasarkan kesimpulan, penulis menyarankan sebagai upaya meningkatkan produksi, KWT dapat menggunakan benih/bibit unggul, karena pada lahan yang sempit, produktivitas benih/bibit unggul tanaman tetap tinggi. KWT juga disarankan menjaga kualitas komoditas hortikultura untuk meningkatkan penjualan produk. Selain produksi dan kualitas, sebagai upaya meningkatkan sumber daya manusia perlu pelatihan atau pendampingan manajemen organisasi pada KWT di Bogor, dan perlu ada penelitian lanjutan tentang potensi dan strategi pengembangan produk unggulan KWT di Kota Bogor. 


\section{UCAPAN TERIMA KASIH}

Penulis mengucapkan terima kasih kepada Kementerian Riset Teknologi/Badan Riset dan Inovasi Nasional karena telah mendanai penelitian ini, serta seluruh petugas Penyuluh Pertanian Kota Bogor, Ketua berserta anggota KWT se-Kota Bogor yang turut membantu dalam pelaksanaan penelitian.

\section{DAFTAR PUSTAKA}

Ahmadi, dan I. (2006). Inovasi Teknologi Pengembangan Pertanian Lahan Rawa Lebak. Inovasi Teknologi Pengembangan Pertanian Lahan Rawa Lebak. Banjarbaru: Balai Penelitian Pertanian Lahan Rawa, Banjarbaru.

Amirin, T. (2011). Populasi Dan Sampel Penelitian 4: Ukuran Sampel Rumus Slovin. Jakarta: Erlangga.

Artanegara, M., Setiawina, N. D., \& Djayastra, K. (2016). Kajian Faktor Sosial Ekonomi Yang Mempengaruhi Produktivitas Petani Asparagus Di Kecamatan Petang Kabupaten Badung. E-Jurnal Ekonomi Dan Bisnis Universitas Udayana, 11, 3741-3764.

Cahya, D. L. (2014). Kajian Peran Pertanian Perkotaan Dalam Pembangunan Perkotaan Berkelanjutan ( Studi Kasus : Pertanian Tanaman Obat Keluarga di Kelurahan Slipi, Jakarta Barat ). Forum Ilmiah, 11(3), 323-333.

De Bon, H., Parrot, L., \& Moustier, P. (2009). Sustainable urban agriculture in developing countries: A review. Sustainable Agriculture, 30 , 619-633. https://doi.org/10.1007/978-90-4812666-8 38

Edi, S. B. J. (2010). Budidaya Tanaman Sayuran. Retrieved from http://dergipark.gov.tr/cumusosbil/i ssue/4345/59412

Kementerian Hukum dan Hak Asasi Manusia, R. I. (2010). Undangundang Republik Indonesia Nomor 13 Tahun 2010 tentang Hortikultura (pp. 1-128). pp. 1128. Jakarta: Kementerian Hukum dan Hak Asasi Manusia, Republik Indonesia.

Nadia. (2018). Kerjasama dengan Pemkot Bogor, PT Bintang Toedjoe Tingkatkan Produksi Jahe Merah. Retrieved from 5 Desember 2018 website:

https://pojoksatu.id/news/beritanasional/2018/12/05/kerjasamapemkot-bogor-pt-bintang-toedjoetingkatkan-produksi-jahe-merah/2/

P2PTM Kemenkes, R. I. (2018). Khasiat dan Manfaat Pisang. Retrieved from

http://www.p2ptm.kemkes.go.id/art ikel-sehat/khasiat-dan-manfaatpisang\#: :text=Buah pisang kaya akan vitamin, bagi tubuh untuk tetap bugar.

Parnata, A. S. (2004). Pupuk Organik Cair. Jakarta: PT Agromedia Pustaka.

Pertanian, D. P. K. P. dan. (2020). Outline Database Kelembagaan Kelompok Wanita Tani Tahun 2020. Bogor.

Putri, Y. P. (2020). Tanaman Hias Aglonema Banyak Diburu Ternyata Punya 7 Fakta Unik, Ada yang Berdaun Emas dan Perak. Retrieved from 29 Agustus 2020 website: https://portaljember.pikiranrakyat.com/gaya-hidup/pr16706253/tanaman-hias-aglonemabanyak-diburu-ternyata-punya-7- 
fakta-unik-ada-yang-berdaun-emasdan-perak

Sa'diyah, A. A., Muljawan, R. E. (2011). Kajian Ekonomi Usahatani Kentang di Kecamatan Sukapura Kabupaten Probolinggo. Buana Sains, 11(1), 71-76.

Slabinski, J. M. (2013). From Wasteland To Oasis: How Pennsylvania Can Appropriate Vacant Urban Land Into Functional Space Via Urban Farming. Widener Law Journal, 22, 253-287.

Soekartawi. (1984). Ilmu Usahatani dan Penelitian untuk Pengembangan Petani Kecil. Jakarta: Universitas Indonesia-Press.

Soekartawi. (2016). Analisis Usahatani. Jakarta: Universitas IndonesiaPress.

Sugiantara, I.G.N. Made \& Utama, M. S. (2019). Pengaruh Tenaga Kerja, Teknologi dan Pengalaman Bertani Terhadap Produktivitas Petani dengan Pelatihan Sebagai Variabel Moderating. Buletin Studi Ekonomi, 24(1), 363-384. Retrieved from https://ojs.unud.ac.id/index.php/eep /article/view/18292/12974
Sugiyono. (2011). Metodologi Penelitian Pendidikan (13th ed.). Bandung: ALFABETA.

Suriadikarta, Didi Ardi., Simanungkalit, R. D. M. (2006). Pupuk Organik dan Pupuk Hayati. Jawa Barat: Balai Besar Penelitian dan Pengembangan Sumberdaya Lahan Pertanian.

Widyawati, R. F. (2013). Pengaruh Umur, Jumlah Tanggungan Keluarga, Luas Lahan, Pendidikan, Jarak Tempat Tinggal Pekerja ke Tempat Kerja, Dan Keuntungan Terhadap Curahan Waktu Kerja Wanita Tani Sektor Pertanian di Desa Tajuk, Kec. Getasan, Kab. Semarang. Universitas Diponogoro, Semarang.

Yulida, R., \& Indraningsih, K. S. (2012). Kontribusi Usahatani Lahan Pekarangan Terhadap Ekonomi Rumah Tangga Petani Di Kecamatan Kerinci Kabupaten Pelalawan. In IJAE (Jurnal Ilmu Ekonomi Pertanian Indonesia) (Vol. 3). https://doi.org/2087-409X 